\title{
The Impact of Word Study Intervention on Adult English Learners' Spelling and Reading
}

\author{
Donita Massengill Shaw \\ University of Kansas, 1122 West Campus Road, Lawrence, KS 66045, USA
}

\begin{abstract}
The purpose of this study was to document the impact of an instructional approach, Word Study, on adults' spelling and reading. Forty-nine adults enrolled in ESL classes at a community-based site in the United States from January through May and were tested on the Comprehensive Adult Student Assessment System, the Elementary Spelling Inventory and the Developmental Spelling Analysis. This study employed a mixed-methodology including statistical and qualitative analyses. The results showed significant growth for the adult students on their spelling and reading scores and positive response to the intervention. Reasons for why this approach is valuable to educators are addressed in the discussion.
\end{abstract}

Index Terms - word study, reading, spelling, adults, English learners

To be proficient in English a person must adequately pronounce words when speaking, possess listening and reading comprehension, decode text while reading, and encode text when writing. Word Study is one instructional approach that will strengthen students' pronunciation, decoding, and encoding. Word Study, built on the conceptual framework of stage development theory (Henderson \& Beers, 1980), is defined as a method for teaching orthography by training learners "to examine, discriminate and make critical judgments about speech sounds, word structures, spelling patterns, and meanings" (Bear, Invernizzi, Templeton, Johnston, 2004, p. 2). Research has shown that English learners progress through the same sequence of developmental stages as native English speakers (Tompkins, Abramson, \& Pritchard, 1999) and that Word Study provides English learners with the vocabulary, spelling and word recognition skills they need to master English (Bear, Helman, Templeton, Invernizzi, \& Johnston, 2007). Several studies have documented the successful use of Word Study intervention with native English speaking adult learners (Hanlon \& Cantrell, 1999; Massengill, 2006; Massengill Shaw, 2008), but missing from the literature is research using Word Study with adult English learners. This research aims to fill the void by documenting Word Study's effectiveness with adults enrolled in English-as-a-second-language (ESL) classes at a community-based site in the southeastern part of the United States.

\section{LITERATURE REVIEW}

A number of studies have researched the effects of a first language (L1) on learning to spell a second language (L2). Sparks, Patton, Ganchow, Humbach and Javorsky (2008) conducted regression analyses on 54 high school students they had followed since first grade. The students were native English speakers and had taken two years of a second language by $10^{\text {th }}$ grade. The researchers found students' L2 spelling was best predicted by students' L1 spelling and phonemic awareness abilities. DeSousa, Greenop and Fry (2011) looked at cross-language relationships for third grade children speaking Afrikaans and English. Thirty bilingual (Afrikaan-English) and 30 monolingual (English) students were asked to spell real and nonsense words in Afrikaans and English. DeSousa, Greenop and Fry found differences in accuracy among the two groups, although the bilingual children had correlated scores on spelling English and Afrikaans. This informs us that there is a cross-language relationship when spelling words in both languages; students' oral language background and their knowledge about language influenced the development of their spelling strategies in two different orthographical languages. The authors also investigated the effects of phonological awareness for Zulu-speaking children as they learned to spell in English. DeSousa, Greenop and Fry (2010) assessed 30 monolingual (English) and 30 bilingual (Zulu and English) second graders. Their findings supported the universal language hypothesis that phonological awareness in L1 supports spelling in L2. Orthographic knowledge relies on phonological awareness (Durgunoglu \& Oney, 2002).

Hguyen-Hoan and Taft (2010) studied bilingual adults who spoke a native language other than English, but had been immersed in English since childhood. They compared bilingual adults' performance to monolingual native English speakers on three tasks: phoneme deletion, spelling to dictation, and auditory comprehension. Hguyen-Hoan and Taft found that even if bilinguals are exposed to English at an early age and are immersed in an English environment, they still process English differently from monolingual native English speakers.

Davidson and Strucker (2002) evaluated word-recognition errors of native and nonnative adult speakers of English who scored between fourth to sixth grade equivalency and were enrolled in Adult Basic Education courses. Results indicated native English speakers made more real-word substitutions than nonnative speakers, but ESL speakers made more phonetically plausible substitutions. The authors reasoned that decoding difficulties have often plagued the native speakers since childhood, whereas the nonnative speakers may transfer some of their first-language decoding knowledge to learning English. 
Al-Jarf (2009) evaluated general and specific spelling strategies of Arabic (mainly a phonetic language) speaking freshmen enrolled in a listening English-as-a-second-language course. The most common strategy used by all Arabic spellers was to substitute an entirely different word than the one they were asked to spell. Poor spellers produced more errors than good spellers; error patterns included deletion of silent letters, reduction of double letters, substitution of a target digraph by another digraph, deletion of vowels, and substitution of a vowel by another vowel or by a digraph. AlJarf provided three reasons students misspelled words: poor knowledge of spelling-sound correspondences, lack of mastery of spelling rules, and poor phonological coding and reliance on orthographic coding. The author concluded English learners' spelling should be treated as a complex developmental process and spelling should be taught directly with reading, writing, listening, and vocabulary.

Instructors of English learners need to be aware of the phonological and orthographical differences of languages, and be able to explicitly teach the comparisons in students' native language with English spelling (Cheung, Chung, Wong, McBride-Chang, Penney, \& Ho, 2010; Sun-Alperin \& Wang, 2008). Davidson and Strucker (2002) stated that ESL teachers should not neglect phonemic, morphemic and orthographic instruction because this would be a detriment to students' future English development.

This study contributes to the field by documenting the impact Word Study instruction has on 49 adult English-as-asecond-language learners' spelling and reading. Questions that guided this study include the following:

1. Did adults who received the Word Study approach make significant gains in their spelling and reading?

2. What did the adult students say about Word Study?

A small sample $(\mathrm{N}=4)$ of adult language learners who did not receive Word Study served as control students and were matched to 4 of the 49 experimental students. Therefore a tertiary question was, "When Word Study students were matched with students who received no Word Study instruction, were there differences in the amount of improvement?"

\section{METHODOLOGY}

This study employs a mixed-methodological design. As Johnson and Onwuegbuzie (2004) stated mixed methods research attempts to draw on the strengths and minimize weaknesses of quantitative and qualitative approaches because both are important and useful. In the field of adult literacy where sample sizes tend to be small and quantitative findings may be limited, mixed methods allows a researcher to use varied data sources to "produce more complete knowledge necessary to inform theory and practice" (p. 21).

Background information

Approximately 550 adults attended the ESL program at Community Adult Education Center in the southeastern part of the United States during the academic year, which was divided into three sessions: mid-August to December, January to mid-June, and July to mid-August. This research study took place during the second session.

Open enrollment allowed students to begin taking classes at any time during the year. Potential students were asked to complete an information sheet with basic facts (address, birthday, country of citizenship) as well as length of time in the United States, previous schooling experiences and occupation. The ESL tester briefly interviewed the incoming students, then administered the Comprehensive Adult Student Assessment System (CASAS, 2001) to determine in which class each student would be placed. The students' Comprehensive Adult Student Assessment System scores ranged from levels 1-6. For instructional purposes, students were grouped into CASAS levels 1/2 (Classroom A), levels 3/4 (Classroom B), and levels 5/6 (Classroom C). Three teachers and their respective leveled classes met in the morning and three teachers with their leveled classes met in the evening January through March. Although students were assigned to classes, they sometimes chose to attend a different class, one that was typically below their level. Only the students who completed this study will be described.

Participants

A total of 49 experimental students who received Word Study took the pre-post tests and are included in the results. There were 31 females and 18 males with an average age of 43 years. Thirty-six Spanish speakers came from a number of countries including Columbia $(\mathrm{N}=12)$ and Mexico $(\mathrm{N}=6)$. Less representative of the Spanish speaking countries include Cuba, Ecuador, Guatemala, Panama, Puerto Rico, Venezuela, Dominican Republic, Chile, El Salvador, and Peru. Three students each spoke Chinese, French and Arabic. Two individuals spoke Vietnamese, and one person each spoke Portuguese, Thai, and Korean. All of the students self-reported reading and writing in their native language. Forty-two students had completed twelfth grade in their home country and 21 had attended a college or university in their homeland. Six of the 21 received degrees from technical/vocational college, nine held bachelor's degrees, five possessed master's degrees and one man held a doctorate degree. The amount of time the students had spent in America ranged from two months to 38 years with the average about 7.63 years.

Four students (one male, three female) served as control and did not receive Word Study instruction. Their average age was 40 years. Two spoke Spanish - one from Mexico and one from Columbia. Two were from China and spoke Mandarin. All reported being literate in their native language. Three had been in America for a short time (months) and one lady had lived in America for three years. Two did not complete high school and one possessed a vocational degree.

Intervention

Class met almost four hours during the morning (8:00-11:45AM) and almost three hours in the evening (6:008:45PM) Monday through Thursday. Students learned a number of skills including listening, speaking, reading and 
writing. Topics included communication (e.g., greeting, giving advice, etc.) finances, rules and regulations, rights and responsibilities, job applications, shopping, doctor visits and many more. Texts such as ExpressWays (Molinsky \& Bliss, 1997) and English in Action (Foley \& Neblett, 2003) were used in the lessons.

Approximately 15-30 minutes during the 3-or-4 hour block of daily class time the teachers instructed experimental students on Word Study. Word Study is a sequential approach to teaching English words. A typical lesson included sorting words, discussing the meaning of words, using words in sentences and conversation, pronunciation of words, and writing the words.

Sorting words according to patterns lies at the heart of Word Study. Students look at a printed word as they say the word being studied. The word is then associated with other words of similar patterns (e.g. home, zone, code) although sometimes phonetic representation diverges, for example the long vowel silent-e pattern words such as home and love. In a sort students are presented with approximately 20 words, each on a separate slip of paper that contain two to four contrasting spelling features (Bear, et al, 2004). Words for the sorts were taken from Word Sorts for Within Word Pattern Spellers (Invernizzi, Johnston, Bear, \& Templeton, 2004) and Word Sorts for Syllables and Affix Spellers (Johnston, Invernizzi, Bear, \& Templeton, 2004). An example of a sort for the syllables and affixes level is 15-20 words that end with doubling a letter (stop - stopping), dropping a letter (hope - hoping), or nothing (track - tracking). After separating the words into their intuitive categories, the learners must make a hypothesis about why some words need a double letter, why some words drop the e, and why some words can have the suffix -ing added without any changes. Once the knowledge is mastered, the students can apply the concept to new and unknown words in future contexts. For example, when given the words whiz or dream, the students should be able to add the -ing and spell the word correctly. Theoretically, anytime the students encounter the words which have a vowel suffix, the students will be able to analyze the word and choose the correct spelling based on the acquired knowledge. Word sorting is "an active process in which students categorize words and pictures to reveal essential differences and similarities among words" (Bear et al., 2004, p. 59).

When students compare and contrast word features, they notice similarities and differences within and across categories that help them, with teacher guidance, to form generalizations about how the words work. As previously noted, it is these generalizations that lend efficiency to word learning because they enable learners to apply what they have discovered to the reading and writing of many other words (Ganske, 2006, p. 4). The inductive reasoning skills required to sort and then articulate the pattern respects the cognitive abilities of adult learners.

Data sources

The Comprehensive Adult Student Assessment System (CASAS) is a standardized assessment used throughout the United States in adult education programs. It possesses strong content and criterion validity and psychometric properties (Flowerday \& Parke, 2005). The reading component measures specific skills such as the ability to understand technical manuals, tax forms, and prescription labels. Students receive a score and are placed in one of the six reading levels described in the National Reporting System (2010). Scores below 180 (foundation) and low beginning 181-190 were levels 1 \& 2 (Classroom A). High beginning 191-200 and low intermediate 201-210 were levels 3 \& 4 (Classroom B). High intermediate 211-220 and advanced placement 221-235 were levels 5 \& 6 (Classroom C). The CASAS was administered to the students by the ESL tester every six weeks. For this research study, the tests scores prior to intervention and closest to the conclusion of the study was obtained for analysis.

All participants were administered the Elementary Spelling Inventory (Bear, Helman, Templeton, Invernizzi, \& Johnston, 2007) pre-post test. The Elementary Spelling Inventory (hereafter ESI) 25 word test contained words representing all stages of development, beginning with bed and progressing to opposition. This test was chosen because it could assess the range of all participants' ability levels: from foundation to academic. One may question the use of 'spelling' tests as a valid measure. Research has shown a reciprocal relationship between spelling and reading (Chall, 1983; Ehri, 1997; Henderson, 1990; Perfetti, 2003). "Spelling is a conservative measure of what students know about words, for if students know how to spell a word, they nearly always know how to read the word" (Bear, et al., 2007, p. 7). Sterbinsky (2007) determined the Elementary Spelling Inventory to be a reliable instrument and a valid predictor of student achievement, including those learning English as a Second Language. The spelling inventory also showed significant relation to elementary/middle school students' standardized test scores. Sterbinsky concluded the Elementary Spelling Inventory is a "valuable addition to any educator's toolbox" (p. 16). The 25-word test was given as a typical spelling test - I read the word, used the word in the sentence and read the word again.

Due to great variance in adults' ability level, the students were also given the Developmental Spelling Analysis (hereafter called DSA) from Word Journeys (Ganske, 2000) as a pre-post test. Students either received the "within word" test or the "syllables and affixes" test. Either 25-word appropriately leveled stage test highlights the features students know, and indicates where their knowledge of spelling patterns and the corresponding sounds are confused or unknown. The DSA was administered as any typical spelling test. I gave students a word, used the word in a sentence, and then the word was dictated again.

A post-questionnaire with two questions was given to participants: What do you think of Word Study? Why do you think/feel this way? Then students were given space to write any additional comments about Word Study they wished to share.

Data collection and analysis 
Quantitative data included pre-post test scores of 25 points for the ESI, (Bear, et al., 2007), DSA 25-point assessment (Ganske, 2000) and CASAS reading (2001) with 235 possible points. In addition, I measured students' knowledge about features of words; a feature is the smallest part of a word that is measureable, such as initial consonant or vowel pattern. Pre-post feature scores were included for the ESI (Bear, et al., 2007) with 53 possible points, and the DSA (Ganske, 2000) for 50 possible points.

All quantitative information was entered in a statistical program. Each student's row of data included pre-post test total scores and pre-post test feature scores as previously mentioned. Additional data in each student's row included attendance, gender, ethnicity, length of time in the United States, self-reported ability to read and write in native language, highest level of schooling and degree obtained. This study was a repeated-measure design with an intervention. A number of statistical analyses were conducted and are described in the results.

Qualitative sources included the open-ended post-questionnaire for students. Traditional case study techniques by Merriam (2009) were employed to analyze the two qualitative questions from the questionnaire. The data were read several times and notes were taken, patterns were identified and pertinent themes established.

\section{RESULTS}

The results will be presented by the guiding research questions. First, attendance will be reported. There were 72 days of school January 4 through May 20. Due to open enrollment I assessed students the beginning of January, midMarch and end of May on the ESI (Bear et al., 2007) and DSA (Ganske, 2000). Eleven students attended January through March with an average of 26 of the 37 days. Another eleven students were tested March to May and attended an average 27 of the 35 days. Twenty-seven students attended the entire semester averaging 56 of the 72 days.

Did adults who received the Word Study approach make significant gains in their spelling and reading?

To answer the first question, paired-sample t-tests were conducted since this research study had a repeated-measures design with an intervention. Each participant had scores on two variables. The first variable represented the pre-test score on each measure and the second variable represented the post-test score on each measure. I was interested to discover if the difference between the two scores was significantly different from zero.

Table 1 displays the raw score mean gains, standard deviations, and p values for the ESI (Bear, et al., 2007). Paired sample t-tests showed there was significant growth on total scores and feature scores for the group as a whole from January-May. Learners' spelling growth measured by their total score on the Elementary Spelling Inventory was $M=5.22, \mathrm{t}(26)=5.06, \mathrm{p}<.00$. The adult students' spelling growth on features of words measured by the ESI (Bear et al., 2007) was $M=8.56, \mathrm{t}(26)=4.74, \mathrm{p}<.00$. The results show standard deviations were high, indicating there was great variability on students' scores in this small sample. Differences among terms were detected.

Table 2 displays the raw score mean gains, standard deviations, and p values for the DSA (Ganske, 2000), both among the group as a whole and disaggregated by term (January-March, March-May, January-May). The students' growth on an ability-leveled spelling measure (Ganske, 2000) for overall total score was $M=3.61, \mathrm{t}(22)=4.05, \mathrm{p}<.00$ and for word features was $M=7.35, \mathrm{t}(22)=4.37, \mathrm{p}<.00$. Once again, differences among terms were noticed.

The reading measure used in this study was The Comprehensive Adult Student Assessment System (CASAS, 2001). A paired sample showed student growth was significant across students $M=8.06, \mathrm{t}(46)=8.79, \mathrm{p}<.00$.

What did the adults say about Word Study?

To answer this question, all student questionnaires reported a positive response to the method. When asked to generate an answer for "What do you think of Word Study?" they responded with the words good/very good, interesting, important/necessary, excellent/great, and helpful. Student A wrote, "I think this is very necessary, interesting. Because this is a tool helpful, that helps us to know new words and to difference the pronunciation between the words." Student B wrote, "Word study is for me very important because I learning lots the rules and the correct spelling, pronunciation, sound and significance the new words." Student C said, "It really helpful because my vocabulary is improving every day. I like this method. It's working for me a lot." Student D said, "It helped and guided me to the first step of learning structure of vowel, sounding and spelling along with grammar." In conclusion Student E wrote, "I would like the teacher continuous with the same method because I think we can learn easily."

When Word Study students were matched with students who received no Word Study instruction, were there differences in the amount of improvement?

Due to the fact that I was only able to collect control data (i.e. no Word Study instruction) on four students, they were paired as close as possible to experimental students based on ESI pre-test scores and other related factors. Table 3 shows the match between experimental-control participants.

I knew this was a convenience sample so I conducted independent samples t-tests to evaluate whether the means for each group were significantly different from each other. There was no significance for ESI $t(6)=2.93, p=.78$; DSA $t(6)=.94, p=.38$; or for the CASAS $t(6)=.82, p=.43$. After I discovered there were no group differences for each of the measures I ran descriptive statistics. Table 4 documents the mean gains from pre-post test for all measures among the two groups. As can be seen, the experimental students consistently made greater improvement on the spelling and reading assessments.

\section{DISCUSSION}


This study inquired about the impact an instructional method could have on adult ESL students' spelling and reading. The results showed a significant increase in learning for students. When analyzing the results it appears that students made greater gains from January to March than from March to May. There may be a few reasons why this occurred. First, spring break and the International food fair took place during the March to May term. Both of these may have influenced instructional time or concentration. A second possibility is the students' learning really 'took off' with a new understanding from January to March, and then their learning consolidated the last portion of the semester so evidence of gains was less noticeable. A third possibility could be the challenge of open enrollment that became more evident during the latter part of the term. Incoming students in March had missed the foundational lessons from January-March and while teachers tried to 'catch them up' they also had to continue teaching the former students who were ready to learn new concepts.

Differences among tests were also noted. The ESI (Bear et al., 2007) contained 25 words that started easy (e.g. bed) and progressively became harder (e.g. opposition) with approximately 7-10 words for each targeted stage: within word and syllables and affixes. Some words included bed, ship, train, place, marched, shower, bottle, favor, cellar, pleasure, fortunate, confident, civilize and opposition. When administering the test, I noted that some words were similar in Spanish and students scored quite well on those words. In contrast, the DSA (Ganske, 2000) contained 25 words for each stage "within word" or "syllables and affixes." While the words on the DSA were not taught by the teacher or studied in lessons, the patterns or generalizations found in the words were similar between instruction and assessment. In order to measure effective growth, there should be a match between instruction and assessment.

The results also indicated when four experimental students were matched to four control students, the experimental students made greater gains. While the conclusions are tentative and only suggestive, there are possible reasons why students who were taught Word Study with fidelity were able to make significantly noticeable progress.

First, Word Study is a developmental approach built on decades of research for children and adults. Longitudinal and cross-grade-level research document the progression for all literacy learners; learners only vary in the rate they acquire the knowledge (Bear, et al., 2004; Tompkins, et al., 1999). Learning to spell in English should be viewed as a developmental process (Al-Jarf, 2009; Bear, et al., 2007); learning to read in English is also developmental (Davidson $\&$ Strucker, 2002). Teachers can move students along the developmental continuum by providing appropriately leveled instruction.

Second, Word Study instruction focuses on the connection between phonological and orthographical knowledge in relation to reading and spelling. Researchers have shown that word recognition and spelling are predicted by phonological awareness (Al-Jarf, 2009; Durgunoglu \& Oney, 2002). Non-native speakers of English "could be helped by the overlearning of phonics principles and syllable patterns and oral reading practice to improve fluency" (Davidson \& Strucker, 2002, p. 313). Further, Davidson and Strucker stated nonnative speakers of English should receive instruction in morphosyntatics and vocabulary. Al-Jarf (2009) advocated for direct instruction in the study of vowel sounds and combining affixes with morphemes. Word Study delivers on these instructional recommendations because it builds students' concepts in a structured and systematic manner that promotes mastery and application.

Third, Word Study appeals to multiple learning styles including visual, auditory and kinesthetic, which have been recommended in the literature (Perez Canado, 2005). Lincoln and Rademacher (2006) investigated learning styles of adult ESL students. Some students preferred aural modes (20\%), while other students favored kinesthetic (15\%), visual $(4 \%)$ or a combination (15\%). So it is important to recognize different modalities benefit all students and to incorporate these into classroom instruction. Sylwester (1995) wrote,

When objects are registered by several senses, they can be stored in several interrelated memory networks. A memory stored in this way becomes more accessible and powerful than a memory stored in just one sensory area, because each sensory memory checks and extends the others (p. 96).

All students benefit from hands-on opportunities to generalize beyond the immediate words to groups of words that have similar spelling characteristics (Juel \& Minden-Cupp, 2000).

Fourth, students' critical thinking in a scaffolded environment was promoted through cross-linguistic transfer and explicit connections across languages; this is important to close the gap for English learners (Bear et al., 2007; Howard \& Snow, 2006). Further, students were not 'told' the rule nor asked to memorize it. Teaching is not telling (James, 1958). Instead, the adult students read the words and inductively reasoned how categories could form and how patterns differed. Then they applied the pattern to more words and compared the pattern to words in their native language (Bear, et al., 2007; Howard \& Snow, 2006). In this manner, students actively constructed their knowledge. Word Study is based on social constructivism: learning often occurs as a result of social interactions with others, language is essential for interaction, and scaffolding by a more competent peer or adult provides assistance for the learning episodes (Vygotsky, 1978, 1986). The teacher provided support through clues, breaking the word into parts, providing examples, and encouraging students (Slavin, 1997).

Fifth, students' newly acquired knowledge was connected to their schema. Schema theory (Piaget, 2001) explains how our cognition is structured in such a way that information we receive is sorted and classified and connected with previously stored knowledge. Schema is acquired, extended and refined throughout life. In this research, learning occurred because students' schema was supported by comparisons among languages, connections between written and oral forms, and opportunities to see conceptual phonological and orthographical relations (Bear, et al., 2007). 
Previous to this intervention, teachers reported they had devoted minimal instructional time to learning about phonics or the English orthographical system. When they did instruct students in phonics and spelling prior to this research study, the rules of English were given as statements to the students and a few words were presented for application of that rule in a more deductive approach. A short time later another rule and new concept would be covered. Sometimes the teacher would have students complete a workbook page with fill-in-the-blank sentences containing a certain feature in the words. The teachers stated their prior instruction had less review and depth as well as limited scope and sequence, and often they did not explicitly teach phonemic, morphemic and orthographic knowledge as recommended (Cheung, et al., 2010; Davidson \& Strucker, 2002; Sun-Alperin \& Wang, 2008).

Despite the positive results, there are always factors that limit research. One limitation of this study was the small sample size in one community-based ESL classroom. Therefore the results cannot be generalized. Another limitation was that no phonemic awareness or first-language assessment was included. A third limitation was the challenge of open enrollment and the CASAS was administered every six weeks instead of at the commencement and conclusion of the study.

Future research with increased sample sizes should conduct regression analyses to determine the impact of the instructional method. It may be possible that students at higher developmental levels may not make as much progress as those at lower levels. This has yet to be documented. Future research should implement a confidence measure to determine the impact Word Study has on students' self-efficacy. Additional research ideas include adding a writing component such as an essay to determine if students transfer and retain their knowledge. A great addition to the research would be to include a vocabulary measure to determine the amount of vocabulary progress students make as a result of learning Word Study. Further, a pronunciation test could be used since accurate pronunciation plays a role in second language spelling (Sawyer \& Joyce, 2006). Future research may also assess whether students who speak languages with deep orthographies make more or less progress in a certain amount of time than students who speak languages with shallow orthographies. The field is ripe for a variety of investigations.

In sum, this study shows that Word Study is not the typical spelling approach used in adult ESL classes that inadequately teaches orthography through memorization and rote learning of words (Perez Canado, 2005). Instead the multisensory approach provides students with explicit instruction that fosters critical thinking and cross-language transfer based on students' developmental needs. It may be concluded that Word Study is a potential method for use in ESL adult classrooms based on increased test scores and positive qualitative responses. The careful study of examining the phonology and orthography of words aims to close the spelling gap for English learners (Howard \& Snow, 2006) and is necessary for students' successful mastery of the English language (Al-Jarf, 2009; Bear et al., 2007; Davidson \& Strucker, 2002). The benefits of such an approach should not be underestimated.

\section{APPENDIX. TABLES}

TABLE 1

PAIRED-SAMPLES T-TEST FOR THE ESI

\begin{tabular}{|c|c|c|c|c|}
\hline Test & & Mean Gain & Standard deviation & $\mathrm{P}$ value \\
\hline \multicolumn{5}{|l|}{ ESI total score ${ }^{\mathrm{a}}$} \\
\hline & Jan-March & 2.81 & 3.32 & .000 \\
\hline & March-May & 2.25 & 4.02 & .003 \\
\hline & Jan-May & 5.22 & 5.37 & .000 \\
\hline \multicolumn{5}{|l|}{ ESI feature score ${ }^{a}$} \\
\hline & Jan-March & 4.86 & 5.36 & .000 \\
\hline & March-May & 3.25 & 5.63 & .003 \\
\hline & Jan-May & 8.56 & 9.38 & .000 \\
\hline \multicolumn{5}{|c|}{${ }^{\mathrm{a}}$ ESI - Elementary Spelling Inventory (Bear, et al., 2007) } \\
\hline \multicolumn{5}{|c|}{ TABLE 2} \\
\hline \multicolumn{5}{|c|}{ PAIRED-SAMPLES T-TEST FOR THE DSA } \\
\hline Test & & Mean Gain & Standard deviation & $\mathrm{P}$ value \\
\hline \multicolumn{5}{|l|}{ DSA total score ${ }^{a}$} \\
\hline & Jan-March & 3.33 & 3.19 & .000 \\
\hline & March-May & 1.90 & 4.37 & .027 \\
\hline & Jan-May & 3.61 & 4.27 & .001 \\
\hline \multicolumn{5}{|l|}{ DSA feature score ${ }^{a}$} \\
\hline & Jan-March & 7.03 & 7.03 & .000 \\
\hline & March-May & 3.72 & 3.72 & .027 \\
\hline & Jan-May & 7.35 & 7.35 & .000 \\
\hline
\end{tabular}

${ }^{\mathrm{a}}$ DSA -Developmental Spelling Analysis (Ganske, 2000) 
TABLE 3

MATCH OF CONTROL AND EXPERIMENTAL STUDENTS

\begin{tabular}{|c|c|c|c|c|c|}
\hline Participants & ESI Total Pre-Test & $\begin{array}{l}\text { CASAS } \\
\text { Pre-Test }\end{array}$ & Attendance & $\begin{array}{l}\text { Highest Education in } \\
\text { Native Country }\end{array}$ & Native Language \\
\hline \multicolumn{6}{|l|}{ Control } \\
\hline Student A & 3 & 193 & 32 & 8 & Spanish \\
\hline Student B & 1 & 197 & 31 & 12 & Chinese \\
\hline Student C & 0 & 195 & 35 & 9 & Chinese \\
\hline Student D & 1 & 197 & 27 & 12 & Spanish \\
\hline \multicolumn{6}{|l|}{ Experimental } \\
\hline Student 1 & 0 & 195 & 28 & 12 & Spanish \\
\hline Student 2 & 0 & 193 & 20 & 12 & Spanish \\
\hline Student 3 & 2 & 197 & 22 & 9 & Spanish \\
\hline Student 4 & 2 & 210 & 23 & 10 & Spanish \\
\hline
\end{tabular}

TABLE 4

MEANS FOR CONTROL AND EXPERIMENTAL STUDENTS

\begin{tabular}{lll}
\hline Test & & $\begin{array}{l}\text { Mean Gain from } \\
\text { Pre-Post Scores }\end{array}$ \\
\hline ESI total score & Control & 1.25 \\
& Experimental & 10.50 \\
ESI feature score & Control & 5.50 \\
& Experimental & 19.75 \\
DSA total score & Control & .75 \\
& Experimental & 7.25 \\
DSA feature score & & \\
& Control & 2.00 \\
& Experimental & 11.00 \\
CASAS & & \\
& Control & 6.25 \\
& Experimental & 8.50 \\
\hline
\end{tabular}

\section{REFERENCES}

[1] Al-Jarf, R. (2009). Listening-spelling strategies in EFL Arab college students. Retrieved July 27, 2010 from http://repository.ksu.edu.sa/jspui/handle/123456789/7716.

[2] Bear, D.R., Helman, L., Templeton, S., Invernizzi, M., \& Johnston, F. (2007). Words their way with English learners. Upper Saddle River, NJ: Merrill Prentice Hall.

[3] Bear, D.R., Invernizzi, M., Templeton, S., \& Johnston, F. (2004). Words their way. Upper Saddle River, NJ: Merrill Prentice Hall.

[4] Chall, J.S. (1983). Stages of reading development. New York: McGraw-Hill.

[5] Cheung, H., Chung, K.K.H., Wong, S.W.L., McBride-Chang, C., Penney, T.B., \& Ho, C.S. (2010). Speech perception, metalinguistic awareness, reading, and vocabulary in Chinese-English bilingual children. Journal of Educational Psychology, 102(2), 367-380.

[6] Comprehensive Adult Student Assessment System (CASAS). (2001). CASAS Technical Manual. San Diego, CA: Author.

[7] Davidson, R.K., \& Strucker, J. (2002). Patterns of word-recognition errors among adult basic education native and nonnative speakers of English. Scientific Studies of Reading, 6(3), 299-316.

[8] DeSousa, D., Greenop, K., \& Fry, J. (2011). Cross-language transfer of spelling strategies in English and Afrikaans grade 3 children. International Journal of Bilingual Education and Bilingualism, 14(1), 49-67.

[9] DeSousa, D.S., Greenop, K., \& Fry, J. (2010). The effects of phonological awareness of Zulu-speaking children learning to spell in English: A study of cross-language transfer. British Journal of Educational Psychology, 80(4), 517-533.

[10] Durgunoglu, A.Y., \& Oney, B. (2002). Phonological awareness in literacy acquisition: It's not only for children. Scientific Studies of Reading, 6(3), 245-266.

[11] Ehri, L.C. (1997). Learning to read and learning to spell are one and the same, almost. In C.A. Perfetti, L. Rieben, \& M. Fayol (Eds.), Learning to spell: Research, theory, and practice across languages (p. 237-269). Mahwah, NJ: Lawrence Erlbaum.

[12] Flowerday, T., \& Parke, C.S. (2005). Test review of Comprehensive Adult Student Assessment System-Third Edition. From R.A. Spies \& B.S. Plake (Eds.), The sixteenth mental measurements yearbook [Electronic version]. Retrieved July 27, 2010 from www.lib.ku.edu.

[13] Foley, B.H., \& Neblett, E.R. (2003). English in action. Boston, MA: Thomson Heinle.

[14] Ganske, K. (2000). Word journeys. New York, NY: Guilford Publications.

[15] Ganske, K. (2006). Word sorts and more: Sound, pattern, and meaning explorations K-3. New York, NY: Guilford Publications.

[16] Hanlon, M.M., \& Cantrell, R.J. (1999). Teaching a learning disabled adult to spell: Is it ever too late? Journal of Adolescent and Adult Literacy, 43(1), 4-11.

[17] Henderson, E. (1990). Teaching spelling ( $2^{\text {nd }}$ ed.). Boston: Houghton-Mifflin.

[18] Henderson, E H., \& Beers, J. (1980). Developmental and cognitive aspects of learning to spell: A reflection of word knowledge. Newark, DE: International Reading Association. 
[19] Hguyen-Hoan, M., \& Taft, M. (2010). The impact of a subordinate L1 on L2 auditory processing in adult bilinguals. Bilingualism: Language and Cognition, 13(2), 217-230.

[20] Howard, E., \& Snow, C. (2006). Spelling as an indicator of English literacy development. Retrieved September 29, 2006 from www.cal.org/acqlit/SubProject3/index.html.

[21] Invernizzi, M., Johnston, F., Bear, D.R., \& Templeton, S. (2004). Word sorts for within word pattern spellers. New York, NY: Pearson.

[22] James, W. (1958). Talks to teachers on psychology and to students on some of life's ideals. New York: Norton.

[23] Johnson, R.B., \& Onwuegbuzie, A.J. (2004). Mixed methods research: A research paradigm whose time has come. Educational Researcher, 33(7), 14-26.

[24] Johnston, F., Invernizzi, M., Bear, D.R., \& Templeton, S. (2004). Word sorts for syllables and affixes spellers. New York, NY: Pearson.

[25] Juel, C., \& Minden-Cupp, C. (2000). Learning to read words: Linguistic units and instructional strategies. Reading Research Quarterly, 35, 458-492.

[26] Lincoln, F., \& Rademacher, B. (2006). Learning styles of ESL students in community colleges. Community College Journal of Research \& Practice, 30(5-6), 485-500.

[27] Massengill, D. (2006). "Mission accomplished. . it's learnable now: Voices of mature challenged spellers using a Word Study approach. Journal of Adolescent \& Adult Literacy, 49(5), 420-431.

[28] Massengill Shaw, D., \& Berg, M. (2008). Effects of a Word Study intervention on spelling accuracy among low-literate adults. Adult Basic Education and Literacy Journal, 2(3), 131-139.

[29] Merriam, S.B. (2009). Qualitative research: A guide to design and implementation. San Francisco: Jossey Bass.

[30] Molinsky, S.J., \& Bliss, B. (1997). ExpressWays. New York: Pearson Longman.

[31] National Reporting System (2010). Retrieved July 27, 2010 from www.nrsweb.org.

[32] Perez Canado, M.L. (2005). English and Spanish spelling: Are they really different? The Reading Teacher, 58(6), 522-530). Doi: 10.1598/RT.58.6.3.

[33] Perfetti, C.A. (2003). The universal grammar of reading. Scientific Studies of Reading, 7(1), 3-24.

[34] Piaget, J. (2001). The psychology of intelligence (M. Piercy \& D.E. Berlyne, Trans.). New York: Routledge.

[35] Sawyer, D.J., \& Joyce, M.T. (2006). Research in spelling: Implications for adult basic education. In J. Comings, B. Garner, \& C. Smith (Eds.), Review of adult language and literacy, volume 6 (pp. 71-112). Mahwah, NJ: Lawrence Erlbaum Associates.

[36] Slavin, R.E. (1997). Educational psychology: Theory and practice ( $5^{\text {th }}$ ed.). Needham Heights, MA: Allyn \& Bacon.

[37] Sparks, R.L., Patton, J., Ganschow, L., Humbach, N., \& Javorsky, J. (2008). Early first-language reading and spelling skills predict later second-language reading and spelling skills. Journal of Educational Psychology, 100(1), 162-174.

[38] Sterbinsky, A. (2007).Words their Way spelling inventories: Reliability and validity analyses. [Technical report]. University of Memphis: Center for Research in Educational Policy.

[39] Sun-Alperin, M.K., \& Wang, M. (2008). Spanish-speaking children's spelling errors with English vowel sounds that are represented by different graphemes in English and Spanish words. Contemporary Educational Psychology, 33(4), 932-948.

[40] Sylwester, R. (1995). A celebration of neurons: An educator's guide to the human brain. Alexandria, VA: Association for Supervision and Curriculum Development.

[41] Tompkins, G.E., Abramson, S., \& Pritchard, R.H. (1999). A multilingual perspective on spelling development in third and fourth grades. Multicultural Education, 6(3), 12-18.

[42] Vygotsky, L S. (1978). Mind in society: The development of higher psychological processes. Cambridge, MA: MIT Press.

[43] Vygotsky, L.S. (1986). Thought and language. Cambridge, MA: MIT Press. (Original work published in 1962).

Donita Massengill Shaw is passionate about helping adults who are becoming literate in English. For over a decade, Donita has completed research on adult literacy interventions including several studies on adult orthography. She also enjoys teaching literacy method and reading specialist courses to pre-service and in-service teachers. 